\title{
Potential Roles of Exercise-Induced Plasma Metabolites Linking Exercise to Health Benefits
}

\author{
Yong Ryoul Yang ${ }^{1}$ and Ki-Sun Kwon ${ }^{1,2 *}$ \\ ${ }^{1}$ Aging Research Center, Korea Research Institute of Bioscience and Biotechnology, Daejeon, South Korea, ${ }^{2}$ Department of \\ Functional Genomics, KRIBB School of Bioscience, Korea University of Science and Technology (UST), Daejeon, South Korea
}

OPEN ACCESS

Edited by:

Katsuhiko Suzuki,

Waseda University, Japan

Reviewed by:

Asghar Abbasi,

Harbor-UCLA Medical Center,

United States

Fabio Demontis,

St. Jude Children's Research

Hospital, United States

Stefanie Tan,

Pfizer, United States

*Correspondence:

Ki-Sun Kwon

kwonks@kribb.re.kr

Specialty section:

This article was submitted to

Exercise Physiology,

a section of the journal

Frontiers in Physiology

Received: 04 September 2020 Accepted: 19 November 2020

Published: 03 December 2020

Citation:

Yang YR and Kwon K-S (2020) Potential Roles of Exercise-Induced Plasma Metabolites Linking Exercise to Health Benefits.

Front. Physiol. 11:602748. doi: 10.3389/fphys.2020.602748
Regular exercise has a myriad of health benefits. An increase in circulating exercise factors following exercise is a critical physiological response. Numerous studies have shown that exercise factors released from tissues during physical activity may contribute to health benefits via autocrine, paracrine, and endocrine mechanisms. Myokines, classified as proteins secreted from skeletal muscle, are representative exercise factors. The roles of myokines have been demonstrated in a variety of exercise-related functions linked to health benefits. In addition to myokines, metabolites are also exercise factors. Exercise changes the levels of various metabolites via metabolic reactions. Several studies have identified exercise-induced metabolites that positively influence organ functions. Here, we provide an overview of selected metabolites secreted into the circulation upon exercise.

Keywords: exercise, metabolites, alpha-ketoglutarate $(\alpha-K G)$, beta-aminoisobutyric acid (BAIBA), kynurenic acid (KYNA), $\beta$-hydroxybutyrate (BHB), lactate, 12,13-diHOME

\section{INTRODUCTION}

Exercise benefits every part of the body and prevents chronic diseases. The effects of exercise are mediated by a complex process involving interorgan crosstalk and activation of integrated body systems at the molecular, cellular, and systemic levels. However, the cellular and molecular mechanisms underlying the effects of exercise are unclear. Omics technologies have made it possible to obtain a huge number of molecular measurements within a tissue, a cell, or plasma during exercise and to comprehensively understand the effects of physical exercise (Pourteymour et al., 2017; Whitham et al., 2018; Pillon et al., 2020). Numerous studies have identified exercise factors that are part of a complex network of interorgan communication. Diverse tissues including skeletal muscle, adipose tissue, bone, and the liver release exercise factors into blood (Moon et al., 2016; Ingerslev et al., 2017; Zhang et al., 2017; Takahashi et al., 2019). These factors contribute to the beneficial effects of exercise, including reduction of adipose mass and inflammation, maintenance of muscle mass, improvement of cardiovascular fitness, and promotion of brain plasticity, as discussed in many previous studies (Hawley et al., 2014). Various types of exercise change whole-body metabolism in both clinical and animal models (Huffman et al., 2014; Starnes et al., 2017; Sato et al., 2019; Schranner et al., 2020). Metabolism plays a crucial role in human health and disease, and is modulated by intrinsic and extrinsic factors. Several exercise-induced metabolites mediate metabolic functions including thermogenesis, glucose homeostasis, and lipolysis (Roberts et al., 2014; Stanford et al., 2018; Yuan et al., 2020). The list of novel metabolites released by exercise continues to grow, aided by advanced omics technologies. However, the roles of many metabolites remain to be tested 
in murine and human in vivo models. Elucidation of the mechanism underlying interorgan crosstalk and biological networking involving exercise factors will help to identify potential therapeutic targets. In this review, we selected six metabolites that have been extensively characterized and have therapeutic potential in metabolic disorders, neurodegenerative diseases, osteosarcoma, or sarcopenia. We summarize our current knowledge of these metabolites, focusing on their biological functions (Figure 1, Table 1).

\section{$\alpha$-KETOGLUTARIC ACID}

$\alpha$-Ketoglutaric acid (AKG) is a crucial intermediate in the TCA cycle required for a rate limiting step (Krebs and Johnson, 1980). AKG is involved in various types of cellular energy metabolism and a variety of metabolic pathways. AKG can be decarboxylated to succinyl-CoA and $\mathrm{CO}_{2}$ by AKG dehydrogenase in the TCA cycle. In addition, AKG is generated from isocitrate by oxidative decarboxylation catalyzed by isocitrate dehydrogenase or anaplerotically from glutamate by oxidative deamination using glutamate dehydrogenase. AKG is a key metabolite in the TCA cycle and is therefore mostly present in mitochondria and the cytoplasm of cells. In addition, AKG is also found in blood (Rocchiccioli et al., 1984; Wagner et al., 2010). Yuan et al. (2020) recently analyzed serum metabolites after acute resistance exercise and found that TCA cycle intermediates are upregulated. Notably, the serum level of $\mathrm{AKG}$ is significantly elevated in response to exercise. In humans, physical exercise increases serum levels of AKG (Lewis et al., 2010; Brugnara et al., 2012). AKG elicits exercise-induced beneficial effects, including muscle hypertrophy and fat loss, through 2-oxoglutarate receptor 1 (OXGR1)-dependent adrenal activation (Yuan et al., 2020). Several studies have shown that AKG activates the mammalian target of rapamycin (mTOR) signaling pathway, resulting in protein synthesis and skeletal muscle hypertrophy (Yao et al., 2012; Cai et al., 2016). AKG inhibits protein degradation and skeletal muscle atrophy through a prolyl hydroxylase 3 (PHD3)/ $\beta 2$ adrenergic receptor (ADRB2)mediated mechanism (Cai et al., 2018). In addition to skeletal muscle, AKG has positive effects on several tissues. AKG injection protects against bone loss in ovariectomized rats (Radzki et al., 2012). AKG supplementation promotes beige adipogenesis through AKG-mediated demethylation in the Prdm16 promoter (Tian et al., 2020). These beneficial effects induced by AKG resemble several changes induced by resistance exercise (Lesinski et al., 2016). These studies suggest that exercise-induced AKG partially contributes to the metabolic effects of exercise.

\section{$\beta$-AMINOISOBUTYRIC ACID}

$\beta$-Aminoisobutyric acid (BAIBA) is a non-proteinogenic amino acid. It is a natural catabolite of thymine and valine metabolism

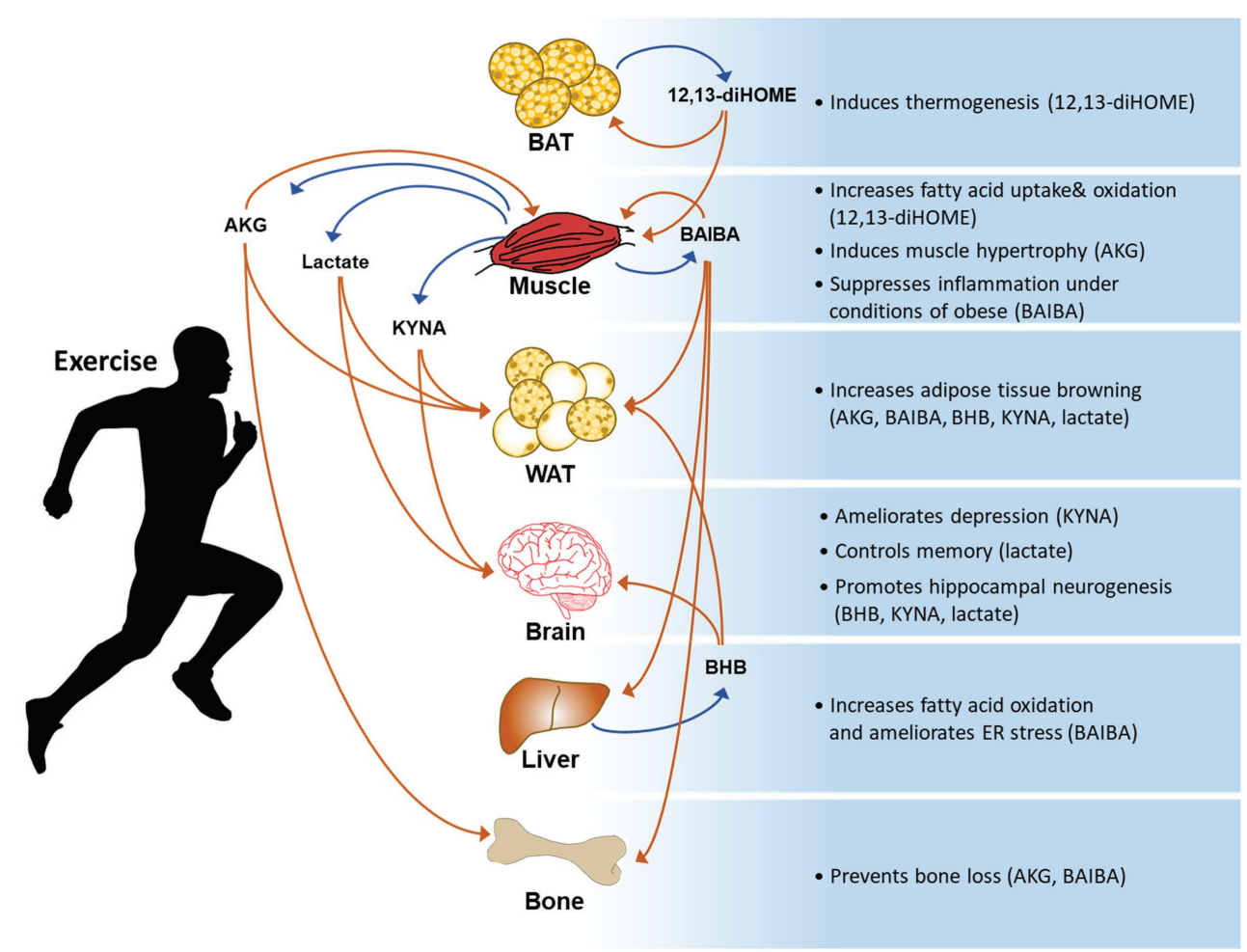

FIGURE 1 | A general summary of exercise-induced metabolites and their effects on the body. AKG: $\alpha$-ketoglutaric acid, BAIBA: $\beta$-aminoisobutyric acid, BHB: $\beta$-hydroxybutyrate, KYNA: kynurenic acid, and 12,13-diHOME: 12,13-dihydroxy-9Z-octadecenoic acid. 
TABLE 1 | Summary of plasma metabolites induced by exercise.

\begin{tabular}{|c|c|c|c|c|c|}
\hline Metabolites & Classes of metabolites & Subjects & Exercise protocol & Main tissue(s) of origin & References \\
\hline$\alpha$-Ketoglutaric acid & A product of glycolysis & $\begin{array}{l}\text { Mouse } \\
\text { Human }\end{array}$ & $\begin{array}{l}\text { Acute resistance exercise (ladder- } \\
\text { climbing) } \\
\text { 26.2-mile marathon } \\
\text { Short-term intensive exercise }\end{array}$ & Skeletal muscle & $\begin{array}{l}\text { Yuan et al., } 2020 \\
\text { Brugnara et al., } 2012 \\
\text { Lewis et al., } 2010\end{array}$ \\
\hline$\beta$-Aminoisobutyric acid & $\begin{array}{l}\text { A product of pyrimidine } \\
\text { metabolism }\end{array}$ & $\begin{array}{l}\text { Human } \\
\text { Mouse }\end{array}$ & $\begin{array}{l}\text { Short-term intensive exercise } \\
3 \text { week free wheel running exercise }\end{array}$ & Skeletal muscle & $\begin{array}{l}\text { Stautemas et al., } 2019 \\
\text { Roberts et al., } 2014\end{array}$ \\
\hline Kynurenic acid & $\begin{array}{l}\text { A product of tryptophan } \\
\text { metabolism }\end{array}$ & $\begin{array}{l}\text { Human } \\
\text { Mouse }\end{array}$ & $\begin{array}{l}\text { Endurance exercise (a 150-km road } \\
\text { cycling time trial) } \\
8 \text { weeks of free wheel running }\end{array}$ & Skeletal muscle & $\begin{array}{l}\text { Schlittler et al., } 2016 \\
\text { Agudelo et al., } 2014\end{array}$ \\
\hline$\beta$-Hydroxybutyrate & $\begin{array}{l}\text { A product of the normal } \\
\text { metabolism of fatty acid }\end{array}$ & $\begin{array}{l}\text { Mouse } \\
\text { Human }\end{array}$ & $\begin{array}{l}4 \text { weeks of free wheel running } \\
\text { Acute exercise (Treadmill running) }\end{array}$ & Liver & $\begin{array}{l}\text { Sleiman et al., } 2016 \\
\text { Kim et al., } 2013\end{array}$ \\
\hline Lactate & $\begin{array}{l}\text { A product of anaerobic } \\
\text { glycolysis }\end{array}$ & $\begin{array}{l}\text { Human } \\
\text { Mouse }\end{array}$ & $\begin{array}{l}\text { Short-term intensive exercise } \\
\text { Acute exercise (Treadmill running) }\end{array}$ & Skeletal muscle & $\begin{array}{l}\text { Juel et al., } 1990 \\
\text { Lonbro et al., } 2019\end{array}$ \\
\hline $\begin{array}{l}\text { 12,13-Dihydroxy-9Z- } \\
\text { octadecenoic }\end{array}$ & $\begin{array}{l}\text { A product of linoleic acid } \\
\text { metabolism }\end{array}$ & Human & Acute exercise (cycle ergometer) & Brown adipose tissue & Stanford et al., 2018 \\
\hline
\end{tabular}

in mammals. There are two enantiomers of BAIBA in biological systems: D-BAIBA (R-BAIBA) and L-BAIBA (S-BAIBA). L-BAIBA is produced via catabolic reactions of $\mathrm{L}$-valine, while $\mathrm{D}$-BAIBA is generated in the cytosol as an intermediate product of thymine degradation (Fink et al., 1956; Kupiecki and Coon, 1957). However, the systemic regulation of their levels is not clearly understood. BAIBA is an exercise-responsive metabolite. Roberts et al. (2014) found that chronic exercise and muscle-specific peroxisome proliferator-activated receptor (PPAR) $\gamma$ coactivator $1 \alpha$ (PGC- $1 \alpha$ ) overexpression increase the plasma level of BAIBA in mice. Stautemas et al. (2019) found that acute aerobic exercise increases the plasma levels of D-BAIBA and L-BAIBA by 13 and 20\%, respectively, and that alanine-glyoxylate aminotransferase 2 (AGXT2) polymorphism only affects the plasma level of D-BAIBA. BAIBA increases expression of brown adipocyte-specific genes in primary adipogenic precursor cells and induces browning in white adipose tissue (WAT) through a PPAR $\alpha$-dependent pathway. BAIBA also increases hepatic fatty acid $\beta$-oxidation. These effects of BAIBA on adipose and liver tissues reduce weight gain and improve glucose tolerance in mice (Roberts et al., 2014). Consistently, BAIBA protects against obesity and related metabolic disorders in mice with partial leptin deficiency (Begriche et al., 2008). In type 2 diabetes model mice, BAIBA ameliorates hepatic endoplasmic reticulum stress, apoptosis, and glucose/lipid metabolic disturbance (Shi et al., 2016). In addition, BAIBA improves palmitate- and high-fat feeding-induced insulin resistance and inflammation, via its action on AMP-activated protein kinase (AMPK) and PPARס in skeletal muscle (Jung et al., 2015). In addition to its metabolic effects, L-BAIBA prevents reactive oxygen species (ROS)-induced apoptosis of osteocytes and loss of bone and muscle. The effects of L-BAIBA are mediated via Mas-related G protein-coupled receptor type D (MRGPRD), and reduced MRGPRD expression with age results in loss of the protective effect of L-BAIBA (Kitase et al., 2018). BAIBA also ameliorates fibrotic responses and renal functional impairment in obstructed kidneys by downregulating the angiotensin (Ang) II/interleukin (IL)-17/ROS signaling pathway (Wang et al., 2017). These reports suggest that BAIBA affects diverse tissues as a mediator of the beneficial effects of exercise.

\section{KYNURENIC ACID}

Tryptophan is not only an $\alpha$-amino acid used to biosynthesize proteins, but is also a precursor of many biologically active compounds such as serotonin, melatonin, and indole. The main route for tryptophan catabolism is through the kynurenine (KYN) pathway. In this pathway, a product of one branch is kynurenic acid (KYNA) and the final product is nicotinamide adenine nucleotide $(\mathrm{NAD}+)$. KYNA is generated in diverse types of peripheral tissues and cells, and is also present in various products consumed by humans. The KYN pathway is responsible for over $90 \%$ of peripheral tryptophan metabolism (Leklem, 1971). KYN and its metabolites are involved in many fundamental biological and pathophysiological processes. Agudelo et al. (2014) found that overexpression of PGC- $1 \alpha 1$ in muscle (mck-PGC- $1 \alpha 1$ ) elevates expression of KYN amino transferases (KATs) 1, 2, and 3, and that exercise training increases KAT expression in skeletal muscle. Importantly, the plasma KYNA level is increased in exercise-trained mice. Interestingly, mck-PGC- $1 \alpha 1$ transgenic mice are resistant to depression. Agudelo et al. suggested that elevated peripheral conversion of KYN to KYNA in skeletal muscle blocks accumulation of neurotoxic KYN metabolites that contribute to the pathogenesis of depression in the brain. Consistently, Schlittler et al. (2016) showed that endurance exercise, but not resistance exercise, increases the plasma KYNA level. In addition to depression, accumulation of KYN and its metabolites in the central nervous system is associated with several psychiatric disorders (Miller et al., 2006; Sellgren et al., 2016). In the brain, KYNA is an antagonist of N-methyl-Daspartate (NMDA) receptors, $\alpha$-amino-3-hydroxy-5-methyl-4isoxazolepropionic acid receptors, kainate receptors, and $\alpha 7$ nicotinic acetylcholine receptor $(\alpha 7 \mathrm{nAChR}$; Perkins and Stone, 1982; Hilmas et al., 2001). By contrast, KYNA acts as an agonist of the G-protein-coupled receptor GPR35 (Wang et al., 2006). Furthermore, KYNA has antioxidant properties (Lugo-Huitron et al., 2011; Perez-Gonzalez et al., 2015). Although the underlying molecular mechanism remains unclear, accumulating evidence suggests that KYNA has neuroprotective properties and there is great therapeutic potential in targeting the muscle KAT-KYN 
pathway in psychiatric disorders. In addition to the brain, Agudelo et al. (2018) found that KYNA functions as a ligand of GPR35 in adipose tissue. A single daily dose of KYNA, which elevates its plasma level to that observed upon exercise, increases systemic energy expenditure through GPR35, which enhances expression of lipid metabolism, thermogenic, and anti-inflammatory genes in adipose tissue. These reports suggest that the beneficial effects of exercise on the brain and adipose tissue might be attributable to an increased level of circulating KYNA.

\section{$\beta$-HYDROXYBUTYRATE}

Ketone bodies are small lipid-derived molecules produced by the liver during fasting and upon prolonged exercise. They are distributed via the circulation to peripheral tissues including skeletal muscle and the brain, where they can be converted to acetyl-CoA (Newman and Verdin, 2014). $\beta$-Hydroxybutyrate (BHB) is the most prevalent ketone body in mammals and plays pivotal roles in whole-body energy metabolism. Much evidence suggests that $\mathrm{BHB}$ is a biologically active metabolite with a broad range of signaling and regulatory effects. BHB is an inhibitor of histone deacetylases (HDACs) and its plasma level is increased after a single bout of acute exercise in mice and human (Kim et al., 2013). Sleiman et al. (2016) revealed that exercise induces brain-derived neurotrophic factor (BDNF) expression in the hippocampus via the action of BHB. They found that BHB released in response to exercise induces BDNF expression by inhibiting HDACs and increases in neurotransmitter release in hippocampus. BDNF has positive effects on memory, cognition, and synaptic transmission. Thus, it is highly conceivable that $\mathrm{BHB}$ can enhance plasticity and improve cognition through BDNF expression. Accumulating evidence suggest that HDAC inhibitors can improve cognitive impairment resulting from neurodegenerative disorders (Graff and Tsai, 2013). Similarly, a recent report revealed that $\mathrm{BHB}$ improves cognitive function in 5XFAD mouse, a widely used AD mouse model, by attenuating $\mathrm{A} \beta$ accumulation and microglia overactivation (Wu et al., 2020). BHB elicits neuroprotective effects against hypoxic and hypoglycemic insults and $\mathrm{N}$-methyl-D-aspartate-induced excitotoxicity (Masuda et al., 2005; Samoilova et al., 2010). BHB attenuates neuroinflammation pathology by inhibiting NLRP3 inflammasome activation in Alzheimer's disease or the spinal cord injury model (Kong et al., 2020; Shippy et al., 2020). Also, BHB prevents postsepsis cognitive impairment (Wang et al., 2020). These multiple studies suggest that BHB may be beneficial in preventing neurodegenerative diseases.

It is noteworthy that butyrate, a broad HDAC inhibitor, improves insulin sensitivity and increases the metabolic rate and oxidative metabolism in a mouse diabetes model (Galmozzi et al., 2013). Thus, the metabolic effects of exercise may be partially attributable to BHB-induced adipocyte browning through a change in the intracellular redox state (Carriere et al., 2014). Ketogenic diets increase the levels of circulating BHB. Ketogenic diets, which contain much fat and little carbohydrate, elevate uncoupling protein 1 (UCP1) expression in brown adipose tissue (BAT) of mice and reduce body weight (Kennedy et al., 2007; Moreno et al., 2014). Additionally, ketogenic diets increase the exercise capacity and show a preventive effect on organ injury caused by acute exercise in mice despite the decrease of absolute muscle volume (Ma et al., 2018). Accumulating evidence indicate that the observed benefit of ketogenic diets might be attributed elevation of circulating BHB. Of note, circulating $\mathrm{BHB}$ is also elevated during caloric restriction (CR) or fasting. CR is widely accepted as positive control of anti-aging intervention (Fontana et al., 2010; Swindell, 2012). BHB has been proposed as a mediator of the beneficial anti-aging effects associated with CR. BHB extends the lifespan of $C$. elegans through inhibiting HDACs and the DAF16/FOXO and SKN-1/Nrf pathways (Edwards et al., 2014). Han et al. (2018) found that BHB prevents p53 independent and octamer-binding transcriptional factor (Oct) four dependent senescence in mouse vascular cells. BHB upregulates Oct4 expression via interacting with heterogeneous nuclear ribonucleoprotein A1 (hnRNP A1), inducing cell quiescence. Intraperitoneal injection of BHB alleviates vascular aging in mice (Han et al., 2018). Because of the BHB roles, it can be considered as a potential mediator of the anti-aging effects of $\mathrm{CR}$ and exercise. Recently, numerous studies have shown that BHB is involved in a variety of cellular functions. BHB promotes generation of claudin- 5 and attenuates diabetesassociated cardiac microvascular hyperpermeablility by inhibiting HDAC3 ( $\mathrm{Li}$ et al., 2020). In aged mice, BHB ameliorated hepatic ER stress and lipid accumulation through the GPR109A/AMPK pathway (Lee et al., 2020). BHB supplementation has also been shown to improve exercise capacity by altering mitochondrial morphology and functions (Monsalves-Alvarez et al., 2020). Taken together, these studies suggest that BHB released upon physical exercise contributes to a wide-range of positive health effects via a number of potential cellular mechanisms.

\section{LACTATE}

Lactate is the ultimate final product of anaerobic glycolysis. Anaerobic exercise induces conversion of pyruvate into lactate by lactate dehydrogenase. Lactate is not metabolized further and is released into blood. Almost $40 \%$ of lactate in the circulation is generated by skeletal muscle (Juel et al., 1990; Adeva-Andany et al., 2014; Lonbro et al., 2019). Maximal exercise can cause a 20 -fold increase in circulating lactate (Goodwin et al., 2007). Many reports have shown that lactate is a signaling molecule released from muscle to communicate with other tissues, such as the brain, the liver, adipose tissue, and the heart (Brooks, 2009). De Matteis et al. (2013) reported that exercise strongly induces expression of the lactate importer MCT1 and increases the metabolic activity of brown adipocytes and suggested that lactate metabolism controls these cells. Carriere et al. (2014) tested the effect of lactate on browning of subcutaneous WAT (scWAT). They found that an increase in browning correlates with an increase in circulating lactate and MCT1 expression in scWAT. Lactate increases thermogenic gene expression in adipocytes via PPARS, and administration of lactate induces 
browning in scWAT of mice. Uptake and metabolism of lactate have been demonstrated in the brain. Lactate uptake by neurons correlates with an increase in the plasma lactate level. Interestingly, lactate use by the brain is related to neuronal activity (Serres et al., 2004; Kemppainen et al., 2005; Dalsgaard, 2006). Lev-Vachnish et al. (2019) identified L-lactate as a factor that promotes adult hippocampal neurogenesis. L-lactate enters neurons through MCT2 and induces formation of new neurons in the dentate gyrus. In addition to neurons, astrocytes regulate memory formation by controlling neuronal lactate transport (Suzuki et al., 2011). Several studies have suggested that increased vascular density is critical for maintaining cognitive function in the brain (Ding et al., 2006; Wightman et al., 2015). Morland et al. (2017) demonstrate that exercise increases brain vascular endothelial growth factor A (VEGFA) protein and angiogenesis via the lactate receptor HCAR1. Moreover, lactate controls blood flow in the brain by increasing vasodilation to obtain more oxygen and glucose when the oxygen concentration is low (Gordon et al., 2008). A number of recent studies implicate the role of lactate in the control of energy intake in rodents and humans. Of note, lactate inhibits both production and activation of ghrelin in gastric mucosal cells (Engelstoft et al., 2013). Lactate also influences appetite through modulating hypothalamic neuropeptide expression and release (Cha and Lane, 2009; Ou et al., 2019). Taken together, these data indicate that lactate is an important metabolic product and that circulating lactate may mediate the beneficial effects of exercise on metabolism and cognition.

\section{2,13-DIHYDROXY-9Z-OCTADECENOIC ACID}

Oxylipins are oxidized metabolites of long-chain polyunsaturated fatty acids (PUFAs). PUFAs can be obtained directly from the diet or from metabolism of linoleic acid and $\alpha$-linolenic acid. Oxylipins are detected in all tissues, urine, and blood (Gabbs et al., 2015). Imbalances in oxylipins correlate with pathological conditions including metabolic disorders, depression, pain, and cardiovascular disease (Caligiuri et al., 2017; Deol et al., 2017; Hennebelle et al., 2017). Linoleic acid can be metabolized via the cytochrome P450 (CYP) pathway to generate 12,13-diHOME. Lipidomics analysis demonstrated that the plasma 12,13-diHOME level increases in response to an acute bout of exercise in humans and mice (Stanford et al., 2018). Exercise-induced 12,13-diHOME is released from BAT. Acute treatment of mice with 12,13-diHOME increases skeletal muscle fatty acid uptake and oxidation (Stanford et al., 2018). Similar to exercise, cold exposure stimulates activation of BAT. Another lipidomic analysis revealed that the plasma 12,13diHOME level is elevated following cold exposure in humans and mice. Injection of 12,13-diHOME facilitates BAT thermogenesis by selectively promoting fatty acid uptake, leading to enhanced cold tolerance. Chronic treatment of diet-induced obese mice with 12,13-diHOME protects against cold challenge and high-fat diet-induced obesity. These results indicate that lipid metabolites participate in regulation of metabolic changes in response to exercise.

\section{CONCLUSION}

Exercise induces release of many regulatory factors into the circulation and these factors influence body changes. Studies have found many exercise factors that link exercise to beneficial effects. Myokines are representative exercise factors secreted by skeletal muscle and affect diverse peripheral tissues as mediators of interorgan crosstalk. Exercise induces great metabolic changes and release of biologically active metabolites into blood. Studies using diverse approaches have identified novel metabolites that link exercise to beneficial effects. Many exercise-induced factors including metabolites and myokines have been reviewed elsewhere (Rai and Demontis, 2016; Murphy et al., 2020).

Investigations have mainly focused on upregulated metabolites that influence tissue functions. Similar to exerciseinduced metabolites, plasma metabolites whose levels are reduced during exercise may play important roles in regulating the beneficial effects of exercise. Indeed, the levels of many plasma metabolites increase with age and some of these metabolites might be associated with aging and age-related diseases (Darst et al., 2019; Yeri et al., 2019). It will be important to investigate the functional role of age-related metabolites whose levels are decreased by exercise. Contrepois et al. (2020) recently performed longitudinal profiling of blood metabolites before and after acute exercise in human and found 728 metabolites affected by exercise. Schranner et al. (2020) identified 196 metabolites that are significantly changed by endurance or resistance exercise in human. These data might be a useful resource to investigate mechanisms of exercise-induced health benefits. Recently, it has been observed that physical exercise modulates gut microbiota in both humans and animals (Clarke et al., 2014; Barton et al., 2018). Of note, bacteria-derived metabolites play critical roles in the modulation of aging and longevity in the host organism (Smith et al., 2017; Shin et al., 2020). Thus, microbiotaderived metabolites could be important mediators of the benefits of exercise. As exercise-induced metabolites have health benefits and reduce the risk of many diseases in humans, elucidation of the roles of exercise-related metabolites and the underlying mechanisms will help to identify novel therapeutic targets for metabolic diseases, including type 2 diabetes and obesity.

\section{AUTHOR CONTRIBUTIONS}

YY and K-SK conceptualized, designed, and wrote the review. K-SK approved the final version of the review. All authors contributed to the article and approved the submitted version.

\section{FUNDING}

This work was supported by National Research Foundation of Korea (NRF) grants funded by the Korean Government (2017M3A9D8048709 and 2019R1C1C1006801) and by the KRIBB initiative program. 


\section{REFERENCES}

Adeva-Andany, M., Lopez-Ojen, M., Funcasta-Calderon, R., AmeneirosRodriguez, E., Donapetry-Garcia, C., Vila-Altesor, M., et al. (2014). Comprehensive review on lactate metabolism in human health. Mitochondrion 17, 76-100. doi: 10.1016/j.mito.2014.05.007

Agudelo, L. Z., Femenia, T., Orhan, F., Porsmyr-Palmertz, M., Goiny, M., Martinez-Redondo, V., et al. (2014). Skeletal muscle PGC-1alpha1 modulates kynurenine metabolism and mediates resilience to stress-induced depression. Cell 159, 33-45. doi: 10.1016/j.cell.2014.07.051

Agudelo, L. Z., Ferreira, D. M. S., Cervenka, I., Bryzgalova, G., Dadvar, S., Jannig, P. R., et al. (2018). Kynurenic acid and Gpr35 regulate adipose tissue energy homeostasis and inflammation. Cell Metab. 27, 378.e5-392.e5. doi: 10.1016/j.cmet.2018.01.004

Barton, W., Penney, N. C., Cronin, O., Garcia-Perez, I., Molloy, M. G., Holmes, E., et al. (2018). The microbiome of professional athletes differs from that of more sedentary subjects in composition and particularly at the functional metabolic level. Gut 67, 625-633. doi: 10.1136/gutjnl-2016-313627

Begriche, K., Massart, J., Abbey-Toby, A., Igoudjil, A., Letteron, P., and Fromenty, B. (2008). Beta-aminoisobutyric acid prevents diet-induced obesity in mice with partial leptin deficiency. Obesity 16, 2053-2067. doi: 10.1038/oby.2008.337

Brooks, G. A. (2009). Cell-cell and intracellular lactate shuttles. J. Physiol. 587, 5591-5600. doi: 10.1113/jphysiol.2009.178350

Brugnara, L., Vinaixa, M., Murillo, S., Samino, S., Rodriguez, M. A., Beltran, A., et al. (2012). Metabolomics approach for analyzing the effects of exercise in subjects with type 1 diabetes mellitus. PLoS One 7:e40600. doi: 10.1371/ journal.pone. 0040600

Cai, X., Yuan, Y., Liao, Z., Xing, K., Zhu, C., Xu, Y., et al. (2018). AlphaKetoglutarate prevents skeletal muscle protein degradation and muscle atrophy through PHD3/ADRB2 pathway. FASEB J. 32, 488-499. doi: 10.1096/ f. 201700670R

Cai, X., Zhu, C., Xu, Y., Jing, Y., Yuan, Y., Wang, L., et al. (2016). Alphaketoglutarate promotes skeletal muscle hypertrophy and protein synthesis through Akt/mTOR signaling pathways. Sci. Rep. 6:26802. doi: 10.1038/ srep26802

Caligiuri, S. P. B., Parikh, M., Stamenkovic, A., Pierce, G. N., and Aukema, H. M. (2017). Dietary modulation of oxylipins in cardiovascular disease and aging. Am. J. Physiol. Heart Circ. Physiol. 313, H903-H918. doi: 10.1152/ajpheart.002 01.2017

Carriere, A., Jeanson, Y., Berger-Muller, S., Andre, M., Chenouard, V., Arnaud, E., et al. (2014). Browning of white adipose cells by intermediate metabolites: an adaptive mechanism to alleviate redox pressure. Diabetes 63, 3253-3265. doi: $10.2337 / \mathrm{db} 13-1885$

Cha, S. H., and Lane, M. D. (2009). Central lactate metabolism suppresses food intake via the hypothalamic AMP kinase/malonyl-CoA signaling pathway. Biochem. Biophys. Res. Commun. 386, 212-216. doi: 10.1016/j.bbrc.2009.06.017

Clarke, S. F., Murphy, E. F., O’sullivan, O., Lucey, A. J., Humphreys, M., Hogan, A., et al. (2014). Exercise and associated dietary extremes impact on gut microbial diversity. Gut 63, 1913-1920. doi: 10.1136/gutjnl-2013-306541

Contrepois, K., Wu, S., Moneghetti, K. J., Hornburg, D., Ahadi, S., Tsai, M. S., et al. (2020). Molecular choreography of acute exercise. Cell 181, 1112.e16-1130.e16. doi: 10.1016/j.cell.2020.04.043

Dalsgaard, M. K. (2006). Fuelling cerebral activity in exercising man. J. Cereb. Blood Flow Metab. 26, 731-750. doi: 10.1038/s.j.jbfm.9600256

Darst, B. F., Koscik, R. L., Hogan, K. J., Johnson, S. C., and Engelman, C. D. (2019). Longitudinal plasma metabolomics of aging and sex. Aging 11, 1262-1282. doi: 10.18632/aging.101837

De Matteis, R., Lucertini, F., Guescini, M., Polidori, E., Zeppa, S., Stocchi, V., et al. (2013). Exercise as a new physiological stimulus for brown adipose tissue activity. Nutr. Metab. Cardiovasc. Dis. 23, 582-590. doi: 10.1016/j. numecd.2012.01.013

Deol, P., Fahrmann, J., Yang, J., Evans, J. R., Rizo, A., Grapov, D., et al. (2017). Omega-6 and omega-3 oxylipins are implicated in soybean oil-induced obesity in mice. Sci. Rep. 7:12488. doi: 10.1038/s41598-017-12624-9

Ding, Y. H., Li, J., Zhou, Y., Rafols, J. A., Clark, J. C., and Ding, Y. (2006). Cerebral angiogenesis and expression of angiogenic factors in aging rats after exercise. Curr. Neurovasc. Res. 3, 15-23. doi: 10.2174/1567202067755 41787
Edwards, C., Canfield, J., Copes, N., Rehan, M., Lipps, D., and Bradshaw, P. C. (2014). D-beta-hydroxybutyrate extends lifespan in C. elegans. Aging 6, 621-644. doi: 10.18632/aging.100683

Engelstoft, M. S., Park, W. M., Sakata, I., Kristensen, L. V., Husted, A. S., Osborne-Lawrence, S., et al. (2013). Seven transmembrane G protein-coupled receptor repertoire of gastric ghrelin cells. Mol. Metab. 2, 376-392. doi: 10.1016/j.molmet.2013.08.006

Fink, K., Cline, R. E., Henderson, R. B., and Fink, R. M. (1956). Metabolism of thymine (methyl-C14 or $-2-\mathrm{C} 14$ ) by rat liver in vitro. J. Biol. Chem. 221, 425-433.

Fontana, L., Partridge, L., and Longo, V. D. (2010). Extending healthy life span--from yeast to humans. Science 328, 321-326. doi: 10.1126/science. 1172539

Gabbs, M., Leng, S., Devassy, J. G., Monirujjaman, M., and Aukema, H. M. (2015). Advances in our understanding of oxylipins derived from dietary PUFAs. Adv. Nutr. 6, 513-540. doi: 10.3945/an.114.007732

Galmozzi, A., Mitro, N., Ferrari, A., Gers, E., Gilardi, F., Godio, C., et al. (2013). Inhibition of class I histone deacetylases unveils a mitochondrial signature and enhances oxidative metabolism in skeletal muscle and adipose tissue. Diabetes 62, 732-742. doi: 10.2337/db12-0548

Goodwin, M. L., Harris, J. E., Hernandez, A., and Gladden, L. B. (2007). Blood lactate measurements and analysis during exercise: a guide for clinicians. J. Diabetes Sci. Technol. 1, 558-569. doi: 10.1177/193229680700100414

Gordon, G. R., Choi, H. B., Rungta, R. L., Ellis-Davies, G. C., and Macvicar, B. A. (2008). Brain metabolism dictates the polarity of astrocyte control over arterioles. Nature 456, 745-749. doi: 10.1038/nature07525

Graff, J., and Tsai, L. H. (2013). The potential of HDAC inhibitors as cognitive enhancers. Annu. Rev. Pharmacol. Toxicol. 53, 311-330. doi: 10.1146/annurevpharmtox-011112-140216

Han, Y. M., Bedarida, T., Ding, Y., Somba, B. K., Lu, Q., Wang, Q., et al. (2018). Beta-hydroxybutyrate prevents vascular senescence through hnRNP A1-mediated upregulation of Oct4. Mol. Cell 71, 1064.e5-1078.e5. doi: 10.1016/j.molcel.2018.07.036

Hawley, J. A., Hargreaves, M., Joyner, M. J., and Zierath, J. R. (2014). Integrative biology of exercise. Cell 159, 738-749. doi: 10.1016/j.cell.2014.10.029

Hennebelle, M., Otoki, Y., Yang, J., Hammock, B. D., Levitt, A. J., Taha, A. Y., et al. (2017). Altered soluble epoxide hydrolase-derived oxylipins in patients with seasonal major depression: an exploratory study. Psychiatry Res. 252, 94-101. doi: 10.1016/j.psychres.2017.02.056

Hilmas, C., Pereira, E. F., Alkondon, M., Rassoulpour, A., Schwarcz, R., and Albuquerque, E. X. (2001). The brain metabolite kynurenic acid inhibits alpha7 nicotinic receptor activity and increases non-alpha7 nicotinic receptor expression: physiopathological implications. J. Neurosci. 21, 7463-7473. doi: 10.1523/JNEUROSCI.21-19-07463.2001

Huffman, K. M., Koves, T. R., Hubal, M. J., Abouassi, H., Beri, N., Bateman, L. A., et al. (2014). Metabolite signatures of exercise training in human skeletal muscle relate to mitochondrial remodelling and cardiometabolic fitness. Diabetologia 57, 2282-2295. doi: 10.1007/s00125-014-3343-4

Ingerslev, B., Hansen, J. S., Hoffmann, C., Clemmesen, J. O., Secher, N. H., Scheler, M., et al. (2017). Angiopoietin-like protein 4 is an exercise-induced hepatokine in humans, regulated by glucagon and cAMP. Mol. Metab. 6, 1286-1295. doi: 10.1016/j.molmet.2017.06.018

Juel, C., Bangsbo, J., Graham, T., and Saltin, B. (1990). Lactate and potassium fluxes from human skeletal muscle during and after intense, dynamic, knee extensor exercise. Acta Physiol. Scand. 140, 147-159. doi: 10.1111/j.17481716.1990.tb08986.x

Jung, T. W., Hwang, H. J., Hong, H. C., Yoo, H. J., Baik, S. H., and Choi, K. M. (2015). BAIBA attenuates insulin resistance and inflammation induced by palmitate or a high fat diet via an AMPK-PPARdelta-dependent pathway in mice. Diabetologia 58, 2096-2105. doi: 10.1007/s00125-0153663-z

Kemppainen, J., Aalto, S., Fujimoto, T., Kalliokoski, K. K., Langsjo, J., Oikonen, V., et al. (2005). High intensity exercise decreases global brain glucose uptake in humans. J. Physiol. 568, 323-332. doi: 10.1113/jphysiol.2005.091355

Kennedy, A. R., Pissios, P., Otu, H., Roberson, R., Xue, B., Asakura, K., et al. (2007). A high-fat, ketogenic diet induces a unique metabolic state in mice. Am. J. Physiol. Endocrinol. Metab. 292, E1724-E1739. doi: 10.1152/ajpendo. 00717.2006 
Kim, K. H., Kim, S. H., Min, Y. K., Yang, H. M., Lee, J. B., and Lee, M. S. (2013). Acute exercise induces FGF21 expression in mice and in healthy humans. PLoS One 8:e63517. doi: 10.1371/journal.pone.0084194

Kitase, Y., Vallejo, J. A., Gutheil, W., Vemula, H., Jahn, K., Yi, J., et al. (2018). Beta-aminoisobutyric acid, l-BAIBA, is a muscle-derived osteocyte survival factor. Cell Rep. 22, 1531-1544. doi: 10.1016/j.celrep.2018.01.041

Kong, G., Liu, J., Li, R., Lin, J., Huang, Z., Yang, Z., et al. (2020). Ketone metabolite beta-hydroxybutyrate ameliorates inflammation after spinal cord injury by inhibiting the NLRP3 inflammasome. Neurochem. Res. doi: 10.1007/ s11064-020-03156-2 [Epub ahead of print]

Krebs, H. A., and Johnson, W. A. (1980). The role of citric acid in intermediate metabolism in animal tissues. FEBS Lett. 117, K1-K10. doi: 10.4159/ harvard.9780674366701.c143

Kupiecki, F. P., and Coon, M. J. (1957). The enzymatic synthesis of betaaminoisobutyrate, a product of valine metabolism, and of beta-alanine, a product of beta-hydroxypropionate metabolism. J. Biol. Chem. 229, 743-754.

Lee, A. K., Kim, D. H., Bang, E., Choi, Y. J., and Chung, H. Y. (2020). Betahydroxybutyrate suppresses lipid accumulation in aged liver through GPR109Amediated signaling. Aging Dis. 11, 777-790. doi: 10.14336/AD.2019.0926

Leklem, J. E. (1971). Quantitative aspects of tryptophan metabolism in humans and other species: a review. Am. J. Clin. Nutr. 24, 659-672. doi: 10.1093/ ajcn/24.6.659

Lesinski, M., Prieske, O., and Granacher, U. (2016). Effects and dose-response relationships of resistance training on physical performance in youth athletes: a systematic review and meta-analysis. Br. J. Sports Med. 50, 781-795. doi: 10.1136/bjsports-2015-095497

Lev-Vachnish, Y., Cadury, S., Rotter-Maskowitz, A., Feldman, N., Roichman, A., Illouz, T., et al. (2019). L-lactate promotes adult hippocampal neurogenesis. Front. Neurosci. 13:403. doi: 10.3389/fnins.2019.00403

Lewis, G. D., Farrell, L., Wood, M. J., Martinovic, M., Arany, Z., Rowe, G. C., et al. (2010). Metabolic signatures of exercise in human plasma. Sci. Transl. Med. 2:33ra37. doi: 10.1126/scitranslmed.3001006

Li, B., Yu, Y., Liu, K., Zhang, Y., Geng, Q., Zhang, F., et al. (2020). Betahydroxybutyrate inhibits histone deacetylase 3 to promote claudin-5 generation and attenuate cardiac microvascular hyperpermeability in diabetes. Diabetologia doi: 10.1007/s00125-020-05305-2 [Epub ahead of print]

Lonbro, S., Wiggins, J. M., Wittenborn, T., Elming, P. B., Rice, L., Pampo, C., et al. (2019). Reliability of blood lactate as a measure of exercise intensity in different strains of mice during forced treadmill running. PLoS One 14:e0215584. doi: 10.1371/journal.pone.0215584

Lugo-Huitron, R., Blanco-Ayala, T., Ugalde-Muniz, P., Carrillo-Mora, P., Pedraza-Chaverri, J., Silva-Adaya, D., et al. (2011). On the antioxidant properties of kynurenic acid: free radical scavenging activity and inhibition of oxidative stress. Neurotoxicol. Teratol. 33, 538-547. doi: 10.1016/j. ntt.2011.07.002

Ma, S., Huang, Q., Yada, K., Liu, C., and Suzuki, K. (2018). An 8-week ketogenic low carbohydrate, high fat diet enhanced exhaustive exercise capacity in mice. Nutrients 10:673. doi: 10.3390/nu10060673

Masuda, R., Monahan, J. W., and Kashiwaya, Y. (2005). D-beta-hydroxybutyrate is neuroprotective against hypoxia in serum-free hippocampal primary cultures. J. Neurosci. Res. 80, 501-509. doi: 10.1002/jnr.20464

Miller, C. L., Llenos, I. C., Dulay, J. R., and Weis, S. (2006). Upregulation of the initiating step of the kynurenine pathway in postmortem anterior cingulate cortex from individuals with schizophrenia and bipolar disorder. Brain Res. 1073-1074, 25-37. doi: 10.1016/j.brainres.2005.12.056

Monsalves-Alvarez, M., Morales, P. E., Castro-Sepulveda, M., Sepulveda, C., Rodriguez, J. M., Chiong, M., et al. (2020). Beta-hydroxybutyrate increases exercise capacity associated with changes in mitochondrial function in skeletal muscle. Nutrients 12:1930. doi: 10.3390/nu12071930

Moon, H. Y., Becke, A., Berron, D., Becker, B., Sah, N., Benoni, G., et al. (2016). Running-induced systemic cathepsin B secretion is associated with memory function. Cell Metab. 24, 332-340. doi: 10.1016/j.cmet.2016.05.025

Moreno, B., Bellido, D., Sajoux, I., Goday, A., Saavedra, D., Crujeiras, A. B., et al. (2014). Comparison of a very low-calorie-ketogenic diet with a standard low-calorie diet in the treatment of obesity. Endocrine 47, 793-805. doi: 10.1007/s12020-014-0192-3

Morland, C., Andersson, K. A., Haugen, O. P., Hadzic, A., Kleppa, L., Gille, A., et al. (2017). Exercise induces cerebral VEGF and angiogenesis via the lactate receptor HCAR1. Nat. Commun. 8:15557. doi: 10.1038/ncomms15557
Murphy, R. M., Watt, M. J., and Febbraio, M. A. (2020). Metabolic communication during exercise. Nat. Metab. 2, 805-816. doi: 10.1038/s42255-020-0258-x

Newman, J. C., and Verdin, E. (2014). Ketone bodies as signaling metabolites. Trends Endocrinol. Metab. 25, 42-52. doi: 10.1016/j.tem.2013.09.002

Ou, Z., Ma, Y., Sun, Y., Zheng, G., Wang, S., Xing, R., et al. (2019). A GPR17cAMP-lactate signaling axis in oligodendrocytes regulates whole-body metabolism. Cell Rep. 26, 2984.e4-2997.e4. doi: 10.1016/j.celrep.2019.02.060

Perez-Gonzalez, A., Alvarez-Idaboy, J. R., and Galano, A. (2015). Free-radical scavenging by tryptophan and its metabolites through electron transfer based processes. J. Mol. Model. 21:213. doi: 10.1007/s00894-015-2758-2

Perkins, M. N., and Stone, T. W. (1982). An iontophoretic investigation of the actions of convulsant kynurenines and their interaction with the endogenous excitant quinolinic acid. Brain Res. 247, 184-187. doi: 10.1016/00068993(82)91048-4

Pillon, N. J., Gabriel, B. M., Dollet, L., Smith, J. A. B., Puig, L. S., Botella, J., et al. (2020). Transcriptomic profiling of skeletal muscle adaptations to exercise and inactivity. Nat. Commun. 11:470. doi: 10.1038/s41467-019-13869-w

Pourteymour, S., Eckardt, K., Holen, T., Langleite, T., Lee, S., Jensen, J., et al. (2017). Global mRNA sequencing of human skeletal muscle: search for novel exercise-regulated myokines. Mol. Metab. 6, 352-365. doi: 10.1016/j. molmet.2017.01.007

Radzki, R. P., Bienko, M., and Pierzynowski, S. G. (2012). Anti-osteopenic effect of alpha-ketoglutarate sodium salt in ovariectomized rats. J. Bone Miner. Metab. 30, 651-659. doi: 10.1007/s00774-012-0377-x

Rai, M., and Demontis, F. (2016). Systemic nutrient and stress signaling via myokines and myometabolites. Annu. Rev. Physiol. 78, 85-107. doi: 10.1146/ annurev-physiol-021115-105305

Roberts, L. D., Bostrom, P., O’sullivan, J. F., Schinzel, R. T., Lewis, G. D., Dejam, A., et al. (2014). Beta-aminoisobutyric acid induces browning of white fat and hepatic beta-oxidation and is inversely correlated with cardiometabolic risk factors. Cell Metab. 19, 96-108. doi: 10.1016/j. cmet.2013.12.003

Rocchiccioli, F., Leroux, J. P., and Cartier, P. H. (1984). Microdetermination of 2-ketoglutaric acid in plasma and cerebrospinal fluid by capillary gas chromatography mass spectrometry; application to pediatrics. Biomed. Mass Spectrom. 11, 24-28. doi: 10.1002/bms.1200110105

Samoilova, M., Weisspapir, M., Abdelmalik, P., Velumian, A. A., and Carlen, P. L. (2010). Chronic in vitro ketosis is neuroprotective but not anti-convulsant. J. Neurochem. 113, 826-835. doi: 10.1111/j.1471-4159.2010.06645.x

Sato, S., Basse, A. L., Schonke, M., Chen, S., Samad, M., Altintas, A., et al. (2019). Time of exercise specifies the impact on muscle metabolic pathways and systemic energy homeostasis. Cell Metab. 30, 92.e4-110.e4. doi: 10.1016/j. cmet.2019.03.013

Schlittler, M., Goiny, M., Agudelo, L. Z., Venckunas, T., Brazaitis, M., Skurvydas, A., et al. (2016). Endurance exercise increases skeletal muscle kynurenine aminotransferases and plasma kynurenic acid in humans. Am. J. Phys. Cell Physiol. 310, C836-C840. doi: 10.1152/ajpcell.00053.2016

Schranner, D., Kastenmuller, G., Schonfelder, M., Romisch-Margl, W., and Wackerhage, H. (2020). Metabolite concentration changes in humans after a bout of exercise: a systematic review of exercise metabolomics studies. Sports Med. Open 6:11. doi: 10.1186/s40798-020-0238-4

Sellgren, C. M., Kegel, M. E., Bergen, S. E., Ekman, C. J., Olsson, S., Larsson, M., et al. (2016). A genome-wide association study of kynurenic acid in cerebrospinal fluid: implications for psychosis and cognitive impairment in bipolar disorder. Mol. Psychiatry 21, 1342-1350. doi: 10.1038/mp.2015.186

Serres, S., Bezancon, E., Franconi, J. M., and Merle, M. (2004). Ex vivo analysis of lactate and glucose metabolism in the rat brain under different states of depressed activity. J. Biol. Chem. 279, 47881-47889. doi: 10.1074/jbc. M409429200

Shi, C. X., Zhao, M. X., Shu, X. D., Xiong, X. Q., Wang, J. J., Gao, X. Y., et al. (2016). Beta-aminoisobutyric acid attenuates hepatic endoplasmic reticulum stress and glucose/lipid metabolic disturbance in mice with type 2 diabetes. Sci. Rep. 6:21924. doi: 10.1038/srep21924

Shin, M. G., Lee, J. W., Han, J. S., Lee, B., Jeong, J. H., Park, S. H., et al. (2020). Bacteria-derived metabolite, methylglyoxal, modulates the longevity of C. elegans through TORC2/SGK-1/DAF-16 signaling. Proc. Natl. Acad. Sci. U. S. A. 117, 17142-17150. doi: 10.1073/pnas.1915719117

Shippy, D. C., Wilhelm, C., Viharkumar, P. A., Raife, T. J., and Ulland, T. K. (2020). Beta-hydroxybutyrate inhibits inflammasome activation to attenuate 
Alzheimer's disease pathology. J. Neuroinflammation 17:280. doi: 10.1186/ s12974-020-01948-5

Sleiman, S. F., Henry, J., Al-Haddad, R., El Hayek, L., Haidar, E. A., Stringer, T., et al. (2016). Exercise promotes the expression of brain derived neurotrophic factor (BDNF) through the action of the ketone body beta-hydroxybutyrate. Elife 5:e15092. doi: 10.7554/eLife.15092

Smith, P., Willemsen, D., Popkes, M., Metge, F., Gandiwa, E., Reichard, M., et al. (2017). Regulation of life span by the gut microbiota in the shortlived African turquoise killifish. Elife 6:e27014. doi: 10.7554/eLife.27014

Stanford, K. I., Lynes, M. D., Takahashi, H., Baer, L. A., Arts, P. J., May, F. J., et al. (2018). 12,13-diHOME: an exercise-induced lipokine that increases skeletal muscle fatty acid uptake. Cell Metab. 27, 1111.e3-1120.e3. doi: 10.1016/j.cmet.2018.03.020

Starnes, J. W., Parry, T. L., O’neal, S. K., Bain, J. R., Muehlbauer, M. J., Honcoop, A., et al. (2017). Exercise-induced alterations in skeletal muscle, heart, liver, and serum metabolome identified by non-targeted metabolomics analysis. Metabolites 7:40. doi: 10.3390/metabo7030040

Stautemas, J., Van Kuilenburg, A. B. P., Stroomer, L., Vaz, F., Blancquaert, L., Lefevere, F. B. D., et al. (2019). Acute aerobic exercise leads to increased plasma levels of R- and S-beta-aminoisobutyric acid in humans. Front. Physiol. 10:1240. doi: 10.3389/fphys.2019.01240

Suzuki, A., Stern, S. A., Bozdagi, O., Huntley, G. W., Walker, R. H., Magistretti, P. J., et al. (2011). Astrocyte-neuron lactate transport is required for long-term memory formation. Cell 144, 810-823. doi: 10.1016/j.cell.2011.02.018

Swindell, W. R. (2012). Dietary restriction in rats and mice: a meta-analysis and review of the evidence for genotype-dependent effects on lifespan. Ageing Res. Rev. 11, 254-270. doi: 10.1016/j.arr.2011.12.006

Takahashi, H., Alves, C. R. R., Stanford, K. I., Middelbeek, R. J. W., Pasquale, N., Ryan, R. E., et al. (2019). TGF-beta2 is an exercise-induced adipokine that regulates glucose and fatty acid metabolism. Nat. Metab. 1, 291-303. doi: 10.1038/s42255-018-0030-7

Tian, Q., Zhao, J., Yang, Q., Wang, B., Deavila, J. M., Zhu, M. J., et al. (2020). Dietary alpha-ketoglutarate promotes beige adipogenesis and prevents obesity in middle-aged mice. Aging Cell 19:e13059. doi: 10.1111/acel.13059

Wagner, B. M., Donnarumma, F., Wintersteiger, R., Windischhofer, W., and Leis, H. J. (2010). Simultaneous quantitative determination of alpha-ketoglutaric acid and 5-hydroxymethylfurfural in human plasma by gas chromatographymass spectrometry. Anal. Bioanal. Chem. 396, 2629-2637. doi: 10.1007/ s00216-010-3479-0

Wang, H., Qian, J., Zhao, X., Xing, C., and Sun, B. (2017). Beta-aminoisobutyric acid ameliorates the renal fibrosis in mouse obstructed kidneys via inhibition of renal fibroblast activation and fibrosis. J. Pharmacol. Sci. 133, 203-213. doi: $10.1016 /$ j.jphs.2016.12.005

Wang, J., Simonavicius, N., Wu, X., Swaminath, G., Reagan, J., Tian, H., et al. (2006). Kynurenic acid as a ligand for orphan $G$ protein-coupled receptor GPR35. J. Biol. Chem. 281, 22021-22028. doi: 10.1074/jbc.M603503200
Wang, X., Song, Y., Chen, J., Zhang, S., Le, Y., Xie, Z., et al. (2020). Subcutaneous administration of beta-hydroxybutyrate improves learning and memory of sepsis surviving mice. Neurotherapeutics 17, 616-626. doi: 10.1007/s13311019-00806-4

Whitham, M., Parker, B. L., Friedrichsen, M., Hingst, J. R., Hjorth, M., Hughes, W. E., et al. (2018). Extracellular vesicles provide a means for tissue crosstalk during exercise. Cell Metab. 27, 237.e4-251.e4. doi: 10.1016/j. cmet.2017.12.001

Wightman, E. L., Haskell-Ramsay, C. F., Thompson, K. G., Blackwell, J. R., Winyard, P. G., Forster, J., et al. (2015). Dietary nitrate modulates cerebral blood flow parameters and cognitive performance in humans: a doubleblind, placebo-controlled, crossover investigation. Physiol. Behav. 149, 149-158. doi: 10.1016/j.physbeh.2015.05.035

Wu, Y., Gong, Y., Luan, Y., Li, Y., Liu, J., Yue, Z., et al. (2020). BHBA treatment improves cognitive function by targeting pleiotropic mechanisms in transgenic mouse model of Alzheimer's disease. FASEB J. 34, 1412-1429. doi: 10.1096/ f. 201901984R

Yao, K., Yin, Y., Li, X., Xi, P., Wang, J., Lei, J., et al. (2012). Alpha-ketoglutarate inhibits glutamine degradation and enhances protein synthesis in intestinal porcine epithelial cells. Amino Acids 42, 2491-2500. doi: 10.1007/s00726011-1060-6

Yeri, A., Murphy, R. A., Marron, M. M., Clish, C., Harris, T. B., Lewis, G. D., et al. (2019). Metabolite profiles of healthy aging index are associated with cardiovascular disease in African Americans: the health, aging, and body composition study. J. Gerontol. A Biol. Sci. Med. Sci. 74, 68-72. doi: 10.1093/ gerona/glx232

Yuan, Y., Xu, P., Jiang, Q., Cai, X., Wang, T., Peng, W., et al. (2020). Exerciseinduced alpha-ketoglutaric acid stimulates muscle hypertrophy and fat loss through OXGR1-dependent adrenal activation. EMBO J. 39:e103304. doi: 10.15252/embj.2019103304

Zhang, J., Valverde, P., Zhu, X., Murray, D., Wu, Y., Yu, L., et al. (2017). Exercise-induced irisin in bone and systemic irisin administration reveal new regulatory mechanisms of bone metabolism. Bone Res. 5:16056. doi: 10.1038/boneres. 2016.56

Conflict of Interest: The authors declare that the research was conducted in the absence of any commercial or financial relationships that could be construed as a potential conflict of interest.

Copyright (c) 2020 Yang and Kwon. This is an open-access article distributed under the terms of the Creative Commons Attribution License (CC BY). The use, distribution or reproduction in other forums is permitted, provided the original author(s) and the copyright owner(s) are credited and that the original publication in this journal is cited, in accordance with accepted academic practice. No use, distribution or reproduction is permitted which does not comply with these terms. 